la revue La revue pour l'histoire du CNRS

POUR LHISTORE DU CNRS $\quad 24 \mid 2009$

Soixante-dixième anniversaire du CNRS

\title{
Au-delà de l'OuralLa recherche anthropologique en Sibérie
}

Émilie Maj et Virginie Vaté

\section{OpenEdition}

Journals

Édition électronique

URL : https://journals.openedition.org/histoire-cnrs/9152

DOI : 10.4000/histoire-cnrs.9152

ISSN : 1955-2408

Éditeur

CNRS Éditions

Édition imprimée

Date de publication : 5 octobre 2009

ISSN : 1298-9800

Référence électronique

Émilie Maj et Virginie Vaté, «Au-delà de l'OuralLa recherche anthropologique en Sibérie », La revue pour I'histoire du CNRS [En ligne], 24 | 2009, mis en ligne le 05 octobre 2009, consulté le 20 mai 2021. URL: http://journals.openedition.org/histoire-cnrs/9152 ; DOI : https://doi.org/10.4000/histoire-cnrs.9152

Ce document a été généré automatiquement le 20 mai 2021.

Comité pour l'histoire du CNRS 


\title{
Au-delà de l'OuralLa recherche anthropologique en Sibérie
}

\author{
Émilie Maj et Virginie Vaté
}

1 Afin d'effectuer un état des lieux de la situation des peuples autochtones, plusieurs expéditions sont organisées par Jean Malaurie (1990) puis par Boris Chichlo (1991, 1993), auxquelles participent de nombreux chercheurs (dont Joëlle Robert-Lamblin et Yvon Csonka).

2 L'intérêt pour cette région du monde n'est pas nouveau et s'inscrit en France dans une longue tradition de recherches. Dès la première moitié $\mathrm{du} \mathrm{XX}^{\mathrm{e}}$ siècle, André LeroiGourhan, élève de Marcel Mauss, présente ses travaux dans La civilisation du renne (1936), une comparaison entre la préhistoire et les peuples de l'Arctique, y compris sibériens. S'inspirant de sa démarche, une nouvelle génération d'ethnoarchéologues (Sylvie Beyries, Francine David, Claudine Karlin...) effectue aujourd'hui des recherches en Sibérie.

Également étudiante de Mauss, Eveline Lot-Falck est d'abord bénévole au musée de l'Homme avant d'être, en 1951, chargée du département Arctique du musée de l'Homme et attachée de recherche au CNRS. Elle publie entre autres Les rites de chasse chez les peuples sibériens (1953). C'est pour elle qu'est créée, en 1963, à la section des sciences religieuses de l'École pratique des hautes études, la chaire des Religions de l'Eurasie septentrionale et de l'Arctique qu'elle dirige jusqu'à sa mort en 1974.

Deux de ses élèves perpétuent cet héritage. Au Musée de l'Homme, elle est remplacée par Laurence Delaby, dont la thèse (1976) est consacrée au chamanisme toungouse et qui publie, notamment, un catalogue analytique des objets chamaniques sibériens du musée de l'Homme (avec Marie-Lise Beffa, en 1999). Roberte Hamayon ${ }^{1}$, attachée de recherche au CNRS à partir de 1965, succède à E. Lot-Falck à la direction de la chaire Religions de l'Asie septentrionale. Elle commence par des recherches linguistiques et ethnologiques en Mongolie et en Bouriatie, puis étend ses analyses aux systèmes religieux des peuples de Sibérie auxquelles elle consacre un doctorat d'État (1988), publié en 1990 sous le titre de La chasse à l'âme: esquisse d'une théorie du chamanisme sibérien. Elle crée en 1969 le Centre d'études mongoles (qui deviendra par la suite Centre 
d'études mongoles et sibériennes) et, en 1970, la revue Études mongoles (aujourd'hui Études mongoles, sibériennes, centrasiatiques et tibétaines). Directeur du laboratoire d'ethnologie et de sociologie comparative de Paris X entre 1988 et 1994, elle est directeur émérite depuis 2007. Anne-Victoire Charrin, professeur à l'Inalco et directrice de l'équipe de recherche Cultures sibériennes: cultures et littératures, et Roberte Hamayon ont dirigé les travaux d'une nouvelle génération de chercheurs. Au sein du Centre d'études mongoles et sibériennes, beaucoup ont inscrit leurs travaux dans le champ du religieux. Parmi eux, on retrouve: Jean-Luc Lambert, élu, en 2003, maître de conférences à la chaire Courants religieux du monde russe et russisé à l'EPHE; V. Vaté, recrutée au CNRS en 2007 ; Alexandra Lavrillier, chercheur post-doctorant à l'institut Max-Plank (EVA, Leipzig); Patrick Plattet, professeur assistant en anthropologie culturelle à l'université d'Alaska-Fairbanks ; Émilie Maj, chercheur post-doctorant au Centre for Landscape and Culture de l'université de Tallinn; enfin, Charles Stepanoff, maître de conférences à l'EPHE, qui a pris la succession de R. Hamayon à la chaire Religions de l'Asie septentrionale et de l'Arctique.

Plusieurs de ces chercheurs sont membres du GDRI « Nomadisme, politiques, religions et croyances dans les espaces turco-mongol et sibérien ». Cette jeune génération de sibérianistes s'est donné pour mission de mettre en avant l'étude de cette zone, encore trop méconnue et pourtant pleine de richesses.

6 À noter :

7 Personnes ayant soutenu une thèse sur la Sibérie depuis 1995 : J.-L. Lambert (1996), M. Leberre-Semenov (2002), V. Vaté (2003), F. Léotar (2004), A. Lavrillier (2005), P. Plattet (2005), C. Ferret (2006), T. Mush (2007), É. Maj (2007), C. Stepanoff (2007).

\section{NOTES}

1. Elle a reçu la médaille d'argent du CNRS en 2006.

\section{RÉSUMÉS}

Dans les années 1990, l'anthropologie de la Sibérie connaît un regain d'intérêt. La perestroïka, puis la désintégration du bloc communiste permettent aux chercheurs non russes de se rendre dans des territoires auparavant difficiles d'accès voire complètement fermés. S'ouvre dès lors un champ inédit d'exploration ethnographique et théorique. 


\section{AUTEURS}

\section{ÉMILIE MAJ}

Émilie Maj est post-doctorante au Centre for Landscape and Culture (Tallinn) et associée en France au Groupe « Sociétés, religions, laïcités » (GSRL, CNRS/EPHE). Ses recherches sont actuellement subventionnées par la Fondation estonienne pour la science.

\section{VIRGINIE VATÉ}

Virginie Vaté est chargée de recherche au CNRS, membre du GSRL. 